\title{
Small-Bowel Bleeding With Laparoscopic Resection Guided by Microcoil Placement
}

\author{
Andrew Dobradin, MD, PhD, Jennifer Suzanne Henson, BS, Alberto Mansilla, MD, \\ Charlene LePane, DO \\ University of Central Florida College of Medicine, Orlando, FL, USA (Drs. Dobradin, LePane). \\ Winter Park Memorial Hospital, Winter Park, FL, USA (Drs. Dobradin, Mansilla, LePane). \\ St. Matthew's University, School of Medicine West Bay, Grand Cayman, KY (Ms. Henson).
}

\begin{abstract}
Introduction: Small-bowel massive bleeding presents a complex diagnostic and therapeutic problem. Angiography can be used for localization and embolization of the overt gastrointestinal bleeding site. Because of the complex anastomotic network of blood vessels supplying the small intestine, precise identification is complicated and surgical resection of the bleeding site is difficult. We describe angiography-directed preoperative microcoil placement for a localization of the bleeding site using intraoperative fluoroscopy during laparoscopic small-bowel resection.
\end{abstract}

Case Description: The described method was used successfully in a 58-year-old woman who was started on a chemotherapy regimen of idarubicin and cytarabine, which has been reported to cause small-bowel hemorrhage, occasionally resulting in fatal outcomes. Overt small intestinal bleeding developed due to enteritis that was unresponsive to conservative therapy and required massive blood transfusions.

Discussion: Many modalities are available for diagnosing and treating obscure small intestinal bleeding when only few of them are suitable for overt bleeding management. We offer an innovative approach that may successfully service the void of an effective technique to treat massive small intestinal bleeding resistant to conservative treatment.

Key Words: Overt gastrointestinal bleeding, Angiography, Surgery, Microcoil, Small intestine.

Citation Dobradin A, Henson JS, Mansilla A, LePane C. Small-bowel bleeding with laparoscopic resection guided by microcoil placement. CRSLS e2014.00273. DOI 10.4293/CRSLS.2014.00273.

Copyright (C) 2014 SLS This is an open-access article distributed under the terms of the Creative Commons Attribution-Noncommercial-ShareAlike 3.0 Unported license, which permits unrestricted noncommercial use, distribution, and reproduction in any medium, provided the original author and source are credited.

Address correspondence to: Andrew Dobradin, MD, PhD, Winter Park Memorial Hospital, 320 N Edinburgh Dr, Ste B, Winter Park, FL 32792, USA. Telephone: (407) 647-3460, Fax: (407) 648-3484, E-mail: adobradin@aol.com

\section{INTRODUCTION}

Small-bowel sources of gastrointestinal bleeding are a diagnostic and therapeutic challenge because of the organ's tortuosity, length, mobility, and complex collateral vasculature. ${ }^{1}$ Various diagnostic and therapeutic procedures are used in small intestine hemorrhage depending on the stability of the patient and the rate of bleeding. ${ }^{2}$ Because small-bowel bleeds are not a common cause of gastrointestinal hemorrhaging, esophagogastroduodenoscopy and colonoscopy are the initial diagnostic methods used to localize the bleeding site in the remainder of the gastrointestinal tract. These methods fail to show the bleeding site in $\sim 5 \%$ of gastrointestinal hemorrhage cases. ${ }^{3}$ The small bowel is the origin of such hemorrhage in $45 \%$ to $75 \%$ of these patients ${ }^{4}$; therefore other techniques must be used to evaluate the small intestine.

A traditional laparotomy with inspection, palpation, transillumination, and enterotomies with direct and enteroscopic inspection and even with a blind resection of the small bowel has a failure rate of 70\%.5 Laparotomy with intraoperative enteroscopy is typically reserved for patients when other identification and treatment modalities have failed because of its inherent high morbidity and mortality rates. ${ }^{2,6}$ We describe a case of laparoscopically assisted small-bowel resection for overt bleeding localized by arteriographic placement of a microcoil. 


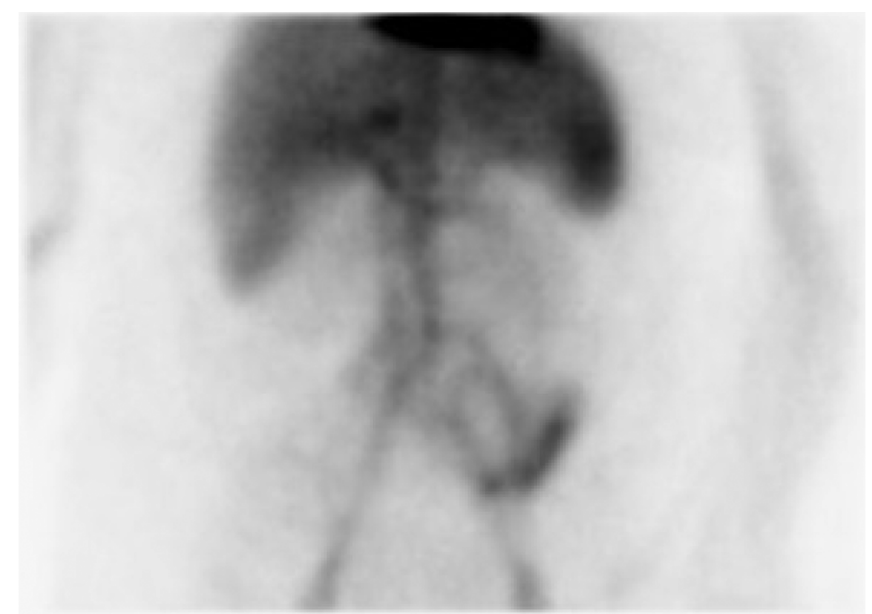

Figure 1. Nuclear imaging scan depicting acute gastrointestinal bleed involving small bowel likely in mid jejunum or proximal ileum.

\section{CASE PRESENTATION}

A previously healthy 58-year-old white woman was admitted for a 4-day history of flulike symptoms associated with leukocytosis and anemia. A bone marrow biopsy was completed and confirmed the diagnosis of acute myelogenous monocytic leukemia. A chemotherapy regimen of idarubicin and cytarabine was started. Complications developed in the form of severe sepsis syndrome: pancytopenia, candidemia, and acute renal failure requiring hemodialysis.

Sepsis syndrome was complicated by gastrointestinal symptoms, watery diarrhea, and abdominal distention, consistent with chemotherapy-induced enteritis. Thrombocytopenia then developed in the patient, with the lowest platelet count being $1 \times 10^{9} / \mathrm{L}$, and coagulopathy developed, with the highest prothrombin time equaling 26.1 seconds. Two weeks later, the patient had massive hematochezia. Emergent upper gastrointestinal endoscopy was performed, but the site of active bleeding could not be visualized. On that day, the patient received a massive transfusion of $17 \mathrm{U}$ of packed red blood cells, $1 \mathrm{U}$ of platelets, and $2 \mathrm{U}$ of fresh-frozen plasma. An emergent nuclear medicine imaging study was completed and determined that the hemorrhage was in the mid jejunum or proximal ileum (Figure 1). Because the location was not definitely identified, we completed mesenteric arteriography of the celiac, superior mesenteric, and inferior mesenteric arteries, which yielded negative findings for an active gastrointestinal hemorrhage.

Because of continual gastrointestinal hemorrhage, arteriography was repeated. This time, arteriography showed focal extravasation of contrast in the left lower quadrant (Figure 2) that correlated with the site of active smallbowel bleeding on the nuclear medicine tagged red blood cell scan. Catheterizations of 3 intestinal branches of the superior mesenteric artery, as well as greater than thirdorder catheterizations, were performed with the intent to identify the bleeding vessel and to proceed with embolotherapy if feasible. However, superselective arteriography failed to show the extravasation of contrast at the thirdorder level despite repeated contrast injections and intraarterial administration of $150 \mu \mathrm{g}$ of nitroglycerin twice. Additional selective superior mesenteric arteriograms also failed to show the site of extravasation of contrast.

After discussion with the consulting general surgeon and gastroenterologist, the decision was made to place an embolization microcoil as close as possible to the site of extravasation of contrast to be used as an intraoperative marking tool during small-bowel resection. A $5 \times 2-\mathrm{mm}$ 0.018-in Tornado microcoil (Cook, Miami Lakes, Florida) was deployed in the distal segment of the second intestinal branch, which supplied the site of bleeding identified on the initial superior mesenteric arteriogram. The arteriogram showed mild short-segment vasospasm at the location of the microcoil without thrombosis or significant flow restriction. The patient was transferred from the angiography suite to the operating room.

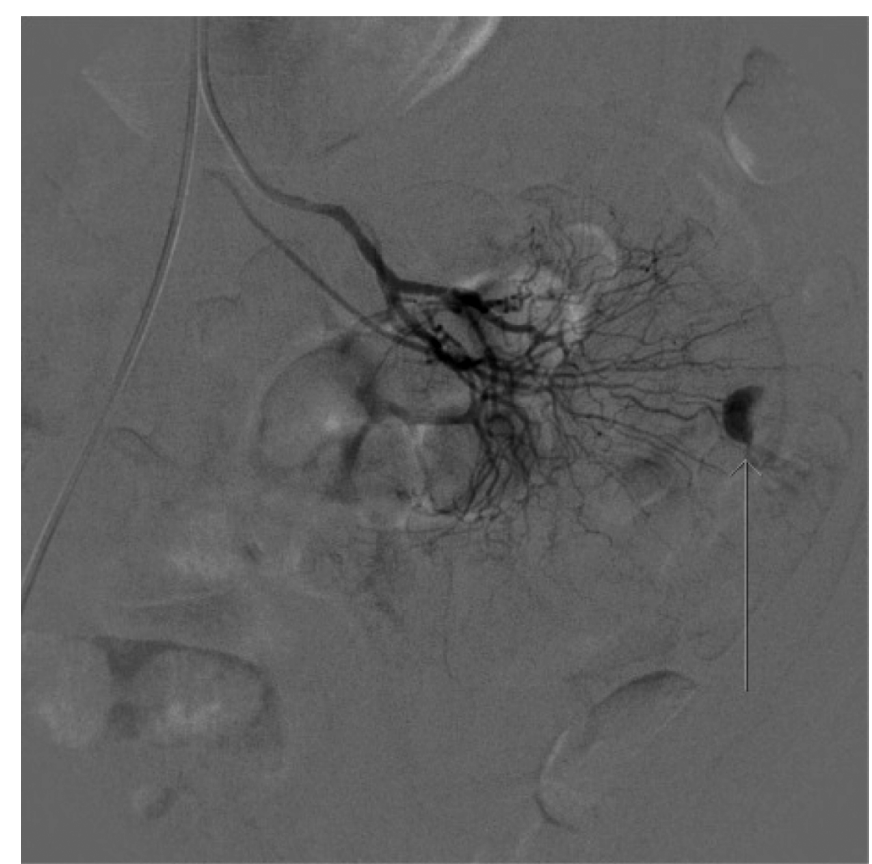

Figure 2. Superior mesenteric arteriography showing active bleed of fifth intestinal branch in jejunal loop. 
The microcoil was clearly visualized under fluoroscopy during exploratory laparoscopy, and the bleeding smallbowel loop was isolated and exteriorized. To guide us toward the affected loop of bowel, corresponding hemoclips were placed on the mesentery to mark the position of the microcoil and avoid unnecessary deep intraperitoneal dissection. Laparoscopically assisted small-bowel resection with primary side-to-side staple anastomosis was performed. Intraoperative flexible endoscopy through the enterotomy of the isolated loop of small intestine was performed but failed to visualize the mucosal pathology that could contribute to the bleeding. There was no gross abnormality of the bowel wall on in vivo inspection. However, there was a large amount of blood found in the exteriorized part of the bowel. The examination of the resected bowel mucosa in the operating room showed shallow ulcerations. Pathologic examination of the resected bowel mucosa showed scattered small foci of epithelial erosion and hemorrhage. On the second postoperative day, the patient once again had a decrease in the hemoglobin level representing acute hemorrhage. With the assumption that the previous resection was insufficient in eliminating the bleeding site, the patient was taken back to the operating room. Exploratory laparotomy, enterotomy with intraoperative enteroscopy, and small-bowel resection of the previous anastomotic site were performed. The additional resection of the anastomosis occurred because enteroscopy lacked evidence of a single-site hemorrhage; however, the blood was present only to the level of the anastomosis, and that area was singled out by the microcoil embolization before. Pathologic examination of the resected specimen showed ulceration with submucosal hemorrhage on the small bowel opposite the anastomotic end.

One day after the operation, a mesenteric arteriogram was completed and ensured that there was no hemorrhage in the remainder of the small bowel. Computed tomography of the abdomen did not show any additional pathology (Figure 3). The patient recovered very well and was discharged home on postoperative day 14. During the hospitalization, she received a total of $49 \mathrm{U}$ of packed red blood cells, $19 \mathrm{U}$ of fresh-frozen plasma, and $16 \mathrm{U}$ of platelets (Figure 4).

\section{DISCUSSION}

Fewer than $10 \%$ of gastrointestinal bleeding cases are related to small-bowel pathology. ${ }^{2}$ Only $0.4 \%$ of all cases of gastrointestinal bleeding are massive. ${ }^{7}$ At this time, there is no effective method for precise diagnosis because

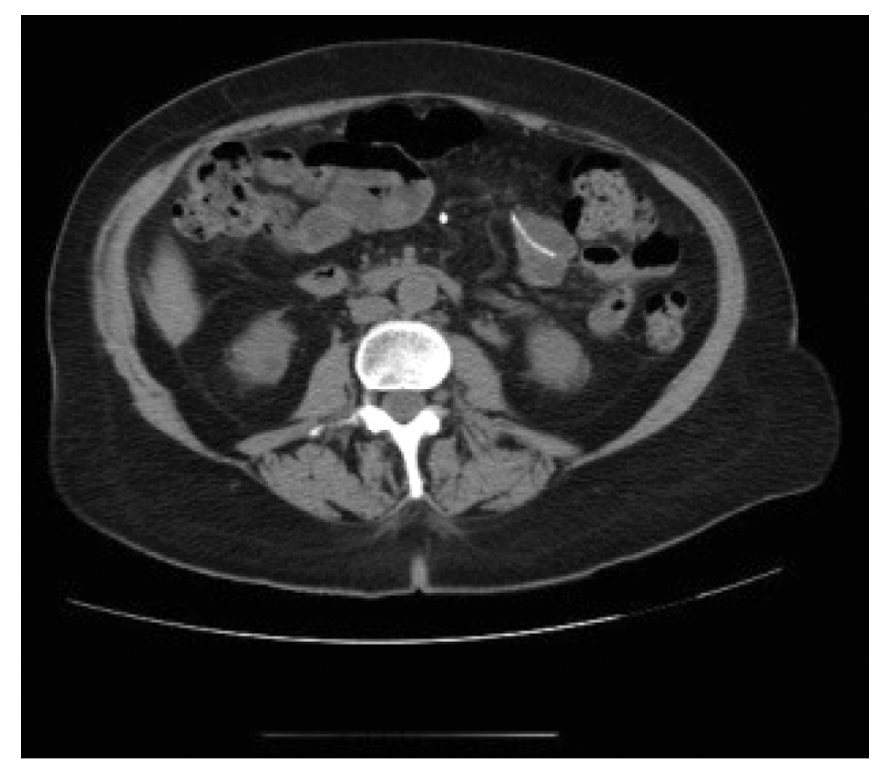

Figure 3. Abdominal computed tomography showing close proximity of microcoil and staple line of small-bowel anastomosis.

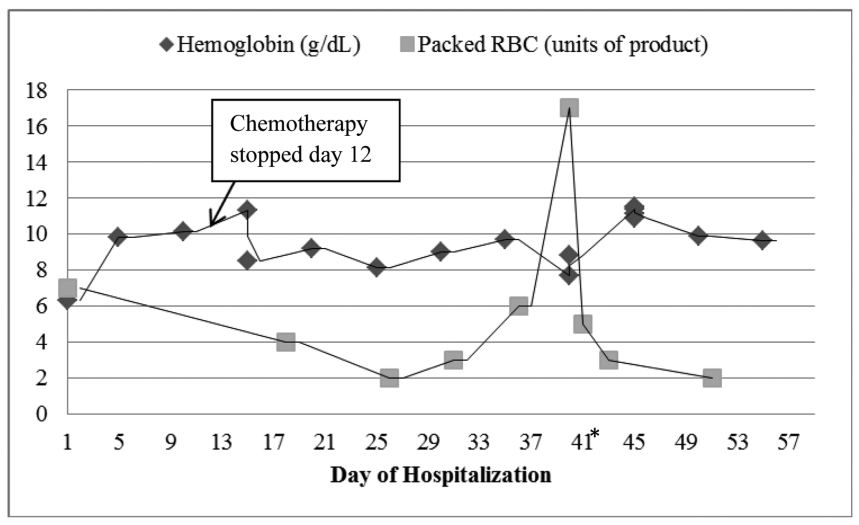

Figure 4. Sudden increase in demand for blood products and stabilization of patient with successful operation on day 41 (asterisk). RBC $=$ red blood cells.

of inconclusive clinical symptoms and signs; therefore the treatment of gastrointestinal bleeding is a challenge for surgeons. ${ }^{7-10}$ Frequently, it requires multiple methods to localize the bleeding site. ${ }^{11,12}$

Endoscopic tools (capsule, double balloon, single balloon, and spiral enteroscopy) for deep small-bowel intubation have shown limited success for small-bowel lesion evaluation, in particular overt bleeding. Even intraoperative enteroscopy has its own limitations. ${ }^{12}$ The average length of the small bowel is 6 to $7 \mathrm{~m}$. Studies such as enteroclysis and small-bowel follow-through provide a 
diagnostic yield as low as 5\% to $10 \%$ in the evaluation of obscure bleeding. ${ }^{13,14}$ Push enteroscopy is a technique that uses a small-bowel enteroscope that has a length of 200 to $220 \mathrm{~cm}$; this technique allows only a maximum of one-third of the entire small proximal bowel to be evaluated. ${ }^{15}$ The diagnostic yield is $\sim 40 \%$ to $60 \%$ for obscure gastrointestinal bleeding. ${ }^{16}$ Capsule endoscopy is also available and can be used in nonacute settings. ${ }^{17}$ Intraoperative enteroscopy is the most complete yet most invasive technique of small-bowel interrogation and provides a diagnostic yield as high as $80 \%$. However, the bleeding site in some patients was identified intraoperatively by external examination, only making the real yield of intraoperative enteroscopy 65\%. ${ }^{4}$ Enteroscopy with intraoperative guidance allows the entire small-bowel mucosa to be explored $^{4,18}$ and would therefore seem to be the most suitable method for identifying the source of small-bowel bleeding. Intraoperative localization of massive bleeding might be an impossible task because preoperative sophisticated radiolabeled scintigraphy and mesenteric arteriography show positive results in $<50 \%$ of brisk bleeding cases.4,19,20 Transcatheter embolization has not been widely accepted as the primary therapy for acute gastrointestinal bleeding because of concerns about producing irreversible intestinal ischemia particularly in the small bowel. ${ }^{21}$ The relative lack of a rich vascular supply to the lower gastrointestinal tract is associated with a greater risk of ischemia than that in the upper gastrointestinal tract. However, transcatheter embolization remains a valuable technique for the control of lower gastrointestinal hemorrhage when endoscopic therapies fail. Surgery is usually reserved for cases of massive hemorrhage unresponsive to medical treatment and minimally invasive techniques because it carries high mortality and morbidity risks in the acute setting, especially in elderly patients. ${ }^{22}$

Investigators have shown that the frequency of intestinal infarction is substantially reduced using superselective transcatheter embolization. ${ }^{23}$ With the development of new microcatheter coaxial systems and embolic agents, superselective embolization is more readily achieved up to the vasa recta and marginal artery. As interventionalists gain more experience with new embolization techniques, there has been increasing interest in the treatment of lower gastrointestinal bleeding with transcatheter embolization.

In our case report, we were unable to primarily treat the small-bowel hemorrhage with superselective embolization because the intermittent nature of the extravasation of contrast did not allow for precise localization of the bleeding vessel. Active small-bowel peristalsis also contributed to difficulty identifying the specific vasa recta responsible for hemorrhage during superselective catheterization. Instead, we decided to place a microcoil in the jejunal branch closest to the site of extravasation to be used as an intraoperative marker during small-bowel resection.

This case is unique in that a technique with radiographic assistance to perform intraoperative small-bowel evaluation was used to identify and subsequently remove the portion of actively bleeding small bowel.

A traditional laparotomy with inspection, palpation, transillumination, and enterotomies with direct and enteroscopic inspection and even with a blind resection of the small bowel has a failure rate of $70 \% .5$

The physical properties of the intestine (hardness, mass, increased vascularity, presence of peristalsis, and flexibility) need to be examined during laparoscopy. 5 Palpation has a diagnostic yield of $30 \%$, but this method does not allow vascular lesions to be localized. ${ }^{5,12,24}$ However, well-defined lesion etiology (diverticulum, tumors, and Meckel diverticulum) is present in $65 \%$ of all small-bowel bleeding cases. ${ }^{25}$

$\mathrm{Ba}$ et $\mathrm{al}^{7}$ completed a study on 22 patients using laparoscopic treatment for massive small intestine bleeding, but all of them were found to have intraoperative pathology by gross visual inspection and only 6 cases required enteroscopy.

We have described the successful treatment of a patient with leukemia in whom dramatic acute hemorrhage developed requiring massive transfusion of blood products. She was in septic condition, and the least invasive approach was highly sought. The unique combination of preoperative placement of the microcoil with intraoperative fluoroscopic identification led the surgeon to the loop of the small bowel causing bleeding. The resection had to be performed again 1 day later because the resected segment of intestine was most likely too short and intraoperative enteroscopy failed to show the site of pathology. Indeed, the pathologic changes were very discrete. The distance of the microcoil from the targeted bleeding vessel might dictate the length of small bowel that needs to be resected. The farther from the bowel the microcoil is, the longer the segment that needs to be resected. The ultimate goal would be to deploy the marking device in direct proximity to the bleeding vessel; however, this was not possible in our case. Guidewire localization is an option, but it has its own shortcomings related to possible migration during transportation and possible arterial thrombosis. ${ }^{11}$ Methylene blue injection through the feeding blood vessel has also been described, but it lacks precision and quickly disperses to the large area of the intestinal mucosa. ${ }^{12}$ 


\section{CONCLUSION}

The arteriographically placed microcoil might mark the loop of bowel that contributes to serious gastrointestinal bleeding. Fluoroscopic guidance is suitable for laparoscopic identification of the offending loop of small intestine. Intraoperative enteroscopy can be used during the operation to identify the bleeding site, but it failed in our case. If the microcoil cannot be placed in the vasa recta, a longer-than-expected segment of small intestine might need to be resected to achieve long-lasting control of the bleeding site. There is not a perfect technique available yet to isolate the small-bowel overt bleeding site of nonpalpable etiologies.

\section{References:}

1. Dye CE, Gaffney RR, Dykes TM, Moyer MT. Endoscopic evaluation of the small bowel in 2012. Am J Med. 2012;125: 1228.e1-1228.e12.

2. Manning-Dimmitt LL, Dimmitt SG, Wilson GR. Diagnosis of gastrointestinal bleeding in adults. Am Fam Physician. 2005;71: 1339-1346.

3. Szold A, Katz LB, Lewis BS. Surgical approach to occult gastrointestinal bleeding. Am J Surg. 1992;163:90-93.

4. Douard R, Wind P, Panis Y, et al. Intraoperative enteroscopy for diagnosis and management of unexplained gastrointestinal bleeding. Am J Surg. 2000;180:181-184.

5. Lau WY, Wong SY, Ngan H, Fan ST, Wong KK. Bleeding small intestinal lesions. Br J Surg. 1988;75:249-251.

6. Zuckerman GR, Prakash C, Askin MP, Lewis BS. AGA technical review on the evaluation and management of occult and obscure gastrointestinal bleeding. Gastroenterology. 2000;118: 201-221.

7. Ba MC, Quing SH, Huang XC, Wen Y, Li GX, Yu J. Application of laparoscopy in diagnosis and treatment of massive small intestinal bleeding: report of 22 cases. World J Gastroenterol. 2006;12(43):7051-7054.

8. Livengood JC, Fenoglio ME. Gastrointestinal hemorrhage from a small bowel polypoid hemangioma. JSLS. 2002;6:179180.

9. Mino A, Ogawa Y, Ishikawa T, et al. Dieulafoy's vascular malformation of the jejunum: first case report of laparoscopic treatment. J Gastroenterol. 2004;39:375-378.

10. Romaozinho JM, Pontes JM, Lerias C, Ferreira M, Freitas D. Dieulafoy's lesion: management and long term outcome. Endoscopy. 2004;36(5):416-420.

11. Unal B, Kutlu R, Aydin C, Kayaalp C. Preoperative angiographic guidewire localization of the bleeding small bowel segment. Surg Laparosc Endosc Percutan Tech. 2011;21: e97-e99.

12. Gifford SM, Peck MA, Reyes AM, Lundy JB. Methylene blue enteric mapping for intraoperative localization in obscure small bowel hemorrhage: report of a new technique and literature review. J Gastrointest Surg. 2012;16:2177-2181.

13. Rabe FE, Becker GJ, Besozzi MJ, et al. Efficacy study of the small bowel examination. Radiology. 1981;140:47-50.

14. Rex DK, Lappas JC, Maglinte DD, et al. Enteroclysis in the evaluation of suspected small intestinal bleeding. Gastroenterology. 1989;97:58-60.

15. Eisen GM, Baron TH, Dominitz JA, et al. Complications of upper gastrointestinal endoscopy. Gastrointest Endosc. 2002; 55(7):784-793.

16. Lin S, Branch MS, Shetzline M. The importance of indication in the diagnostic value of push enteroscopy. Endoscopy. 2003; 35:315-321.

17. Yamashita K, Okumura H, Oka Y, et al. Minimally invasive surgery using intraoperative real-time capsule endoscopy for small bowel lesions. Surg Endosc. 2013;27:2337-2341.

18. Bowden TA. Intraoperative endoscopy of the gastrointestinal tract: clinical necessity or lack of preoperative preparation? World J Surg. 1989;13:186-189.

19. Suzman MS, Talmor M, Jennis R, Binkert B, Barie PS. Accurate localization and surgical management of active lower gastrointestinal hemorrhage with technetium-labeled erythrocyte scintigraphy. Ann Surg. 1996;224:29-36.

20. Pennoyer WP, Vignati PV, Cohen JL. Mesenteric angiography for lower gastrointestinal hemorrhage. Dis Colon Rectum 1997;40:1014-1018.

21. Evangelista PT, Hallisey MJ. Transcatheter embolization for acute lower gastrointestinal hemorrhage. J Vasc Interv Radiol. 2000;11:601-606.

22. Kickuth R, Rattunde H, Gschossmann J, et al. Acute lower gastrointestinal hemorrhage: minimally invasive management with microcatheter embolization. J Vasc Interv Radiol. 2008; 19(9):1289-1296.e2.

23. Ledermann HP, Schoch E, Jost R, Decurtins M, Zollikofer CL. Superselective coil embolization in acute gastrointestinal hemorrhage: personal experience in 10 patients and review of the literature. J Vasc Interv Radiol. 1998;9:753-760.

24. Retzlaff JA, Hagedron AB, Bartholomew LG. Abdominal exploration for gastrointestinal bleeding of obscure origin. JAMA. 1961;177(2):94-97.

25. Ramirez FC. Small bowel bleeding. Curr Treat Options Gastroenterol. 1999;2:355-362. 